\title{
UM ENSAIO INICIAL: A LUTA ECOLÓGICA COMO FONTE DE EDUCAÇÃO AMBIENTAL NÃO FORMAL DA INDUSTRIALIZAÇÃO AO SURGIMENTO DO MOVIMENTO ECOLÓGICO EM RIO GRANDE/RS
}

\author{
Antonio Carlos Porciuncula Soler ${ }^{1}$, Eugênia Antunes Dias ${ }^{2}$, Francisco Veras Quintanilha ${ }^{3}$
}

\begin{abstract}
RESUMO
A visão antropocêntrica de natureza, construída historicamente, ao lado da economia capitalista, constituem as bases para a crise ecológica $\mathrm{Na}$ década de 60 o mundo viveu um processo de industrialização. Contestando esse modelo societário a luta ecológica teve seu nascedouro naquele momento. A EANF deve contemplar ações voltadas à sensibilização da coletividade e à sua organização e participação na defesa da qualidade do meio ambiente. Contudo, mais que a aparência da EA (Formal ou Não-Formal) importa seu conteúdo, ou seja, se a EA se propõe a transformar ou manter a realidade opressora, geradora da crise. No caso do munícipio de Rio Grande, com o projeto de crescimento econômico não só levou a ampliação do número de indústrias, como contribui para o surgimento do movimento ecológico, destacadamente através do CEA, o qual foi pioneiro na EANF. A EA (formal ou não formal) para ser considerada transformadora, deve ter, no mínimo, um duplo papel: superar a crise social e a ecológica, combatendo o paradigma capitalista/antropocêntrico.
\end{abstract}

PALAVRAS-CHAVE: Educação Ambiental Não Formal. Movimento Ambiental/Ecológico. Crise Ecológica

\begin{abstract}
The anthropocentric view of nature, historically constructed next to the capitalist economy to constitute the basis for the ecological crisis In the 60s the world experienced an industrialization process. Contesting this corporate model ecological struggle had its birth at that time. The EANF should include actions aimed at raising awareness of the community and their organization and involvement in protecting the quality of the environment. However, more than the appearance of a (formal or non-formal) matter its content, that is, if the EA proposes to make or keep the oppressive reality, generating the crisis. In the case of the municipality of Rio Grande, with economic growth project not only led to increasing the number of industries, and contributes to the emergence of the ecological movement, notably through the CEA, which pioneered the EANF. EA (formal or informal) to be considered manufacturing, must have at least a dual role: to overcome the social crisis and the ecological, fighting the capitalist paradigm / anthropocentric.

KEYWORDS: Environmental Non-Formal Education. Environmental / Ecological Movement. Ecological crisis

1 Graduação em Direito (FURG), especialista em Ecologia Humana (UNISINOS) e Ciência Política (ISP/UFPel), mestre e doutorando em Educação Ambiental (PPGEA/FURG).

2 Doutora Educação Ambiental/PPGEA/FURG, Pró-Reitora de Gestão de Pessoas da UFPel e membro do Centro de Estudos Ambientais (CEA).

3 Doutor. Professor da FURG.
\end{abstract}




\section{INTRODUÇÃO}

O presente artigo pretende realizar uma reflexão acerca da crise ambiental e das possibilidades da Educação Ambiental Não Formal (EANF) para sua superação, dando ênfase aos impactos paradigmáticos do antropocentrismo vigente e a própria desigualdade de classes que ocasiona a proliferação de situações de injustiça ambiental delegando, de forma reducionista, a Educação Ambiental (EA) em escolas, por exemplo, programas de reciclagem ou plantio de árvores.

A EANF também se volta para programas institucionais empresariais previstos em licenciamentos ambientais, muitas vezes com mera intenção publicitária, de marketing ecológico dentro de estratégias de certificação do "ecocapitalismo".

A presente pesquisa intenta estabelecer que a distinção da EA deve ser efetivada pelo seu conteúdo, verificando se a mesma, se volta para lutas contra a opressão, destruição da natureza e pela transformação da sociedade rumo ao fim das injustiças ambientais $^{4}$ e a visão antropocêntrica mantida pela cultura, economia e ciência contemporâneas.

Neste sentido dentro cenário de Rio Grande, o artigo busca retratar a destruição do ecossistemas com a proliferação de danos e impactos ambientais desde a invasão e poluição de áreas de preservação permanente (APPs) até a poluição atmosférica por indústrias de fertilizantes.

Por fim, este ensaio procura retratar a reconstituição de aspectos da luta ecológica política do Centro de Estudos Ambientais (CEA), visando a transformação societária através da ação direta, midiática empreendida pela EANF, especialmente dentro da sua ação de décadas realizada na metade sul do Rio Grande do Sul.

\section{A CRISE PRODUZINDO A LUTA ECOLÓGICA}

\footnotetext{
4 Cabe destacar que a Rede Brasileira de Justiça Ambiental (RBJA) entende por Injustiça Ambiental o "mecanismo pelo qual sociedades desiguais, do ponto de vista econômico e social, destinam a maior carga dos danos ambientais, do desenvolvimento, às populações de baixa renda, aos grupos raciais discriminados, aos povos étnicos tradicionais, aos bairros operários, às populações marginalizadas e vulneráveis" (ACSELRAD, MELLO e BEZERRA, 2009, p. 41). Em contraponto, a RBJA persegue a Justiça Ambiental, "compreendida como o tratamento justo e o envolvimento pleno dos grupos sociais, independentemente de sua origem ou renda, nas decisões sobre o acesso, a ocupação e o uso dos recursos ambientais em seus territórios" (ACSELRAD, MELLO e BEZERRA, 2009, p. 41).
} 
Nos anos 60/70, do século passado, as consequências da crise ecológica global não eram tão explicitas como são na atualidade, mas já apresentavam indicadores importantes para a leitura e compreensão dos seus fundamentos, os quais a sustentam até o presente, porém de forma mais intensa. É fato que a leitura dessa crise contava com alguns obstáculos, além de seu encobrimento, típico de fenômenos emergentes, para seu claro entendimento. Incidia sobre ela uma (Des) Educação Ambiental construída por setores do capital, direcionada por décadas em negá-la, o chamado negacionismo ${ }^{5}$.

Contrariamente, ao passo que percebia tais fenômenos da degradação ambiental planetária, acompanhado de uma imensa desigualdade social, notadamente nos países pobres, a qual, em linhas gerais, se aprofundou no Brasil e no mundo, o movimento ecológico ${ }^{6}$ contemporâneo emergiu e organizou-se em torno da bandeira da contestação do modelo econômico hegemônico, gerador da crise. "El ecologismo nos proporciona una crítica de los modelos actuales de produccion y consumo (DOBSON, 1999, p.155).

Assim, o ecologismo chamou a atenção para a ameaça à vida (humana e não humana) que tal paradigma representava e ainda representa, defendendo ideias anticapitalistas, não necessariamente a esquerda da política (PEPPER, 1996, p.289). O destaque dado as ameaças a vida local e planetária, pelo ecologismo de então, serviu como critica de seus opositores, os quais o chamavam de alarmista e/ou apocalíptico, entre outras tentativas de descredito, a qual, em determinada medida, foi decorrente daquele negacionismo deliberado. Aliás, cabe a reflexão, quem é de fato apocalíptico, quem o critica ou quem o promove?

Nessa esteira, a luta ecológica teve por motivação primeira, ainda na década de 60 , a contestação do modelo societário produtivista, consumista e injusto ${ }^{7}$, combatendo o $^{\circ}$ dano ambiental e as desigualdades sociais decorrentes desse paradigma, desde o inicio perseguindo provocar um processo de conscientização dessa relação opressora, para tanto, já se valendo de alguma forma da EA.

5 Postura adotada e propagada por grupos econômicos e setores sociais que negavam, por motivações diversas, estudos que demonstravam a existência da crise ecológica, destacadamente com relação as mudanças climáticas.

$6 \mathrm{O}$ ecologismo é "conjunto de ideias referidas al médio ambiente que se pueden considerar propiamente como uma ideologia" (DOBSON, 1997, p.21).

7 Chega a $91,6 \%$ a população mundial não tem acesso ao mínimo de conforto material, detendo "apenas $16,7 \%$ da riqueza global" (MARQUES, 2015, p.16). 
Atualmente, essa ameaça, mais estudada, mais discutida e documentada, se apresenta de forma também mais clara, sendo apontada por diversos autores como decorrente do modelo capitalista de sociedade.

O modo de produção e de consumo atual dos países capitalistas avançados, fundado numa lógica de acumulação ilimitada (do capital, dos lucros, das mercadorias), do esgotamento dos recursos, do consumo ostentatório, e da destruição acelerada do meio ambiente, não pode, de modo algum, ser expandido para o conjunto do planeta, sob pena de uma crise ecológica maior. (LOWY, 2005, p.49)

Outro fator, ao lado do modelo econômico, problematizado como responsável da crise em questão é a visão antropocêntrica de natureza, pois "se hay uma palabra que sostiene la gama entera de objeciones verdes radicales a las atuales formas de conducta humana em el mundo, ésa es probablemente 'antropocentrismo"” (DOBSON, 1997, p.84).

Tal visão de natureza é culturalmente construída (GONÇALVES, 2004, p. 22) nas relações sociais, fazendo com que, associada a supervalorização do aspecto econômico, notadamente o capitalista,

do ponto de vista ambiental, a natureza seja vista na condição de simples recurso para a produção de bens. Sua utilização, em forma e intensidade, fica subordinada aos interesses econômicos (...) O Antropocentrismo e o cálculo econômico levam ao resultado social da fetichização da taxa de crescimento econômico: elevação dessa taxa sendo tomada pelo que efetivamente não é, ou seja, como equivalente à melhoria das condições de vida da sociedade (MONTIBELLER-FILHO, 2008, p.50)

Assim, nos deparamos diante da ameaça de um colapso global, com impactos negativos social e ambientalmente, desafiando os movimentos ecológicos/ambientais a pensarem e praticarem uma EA capaz de compreender e superarem a crise atual.

A crise ecológica é a crise do nosso tempo. O risco ecológico questiona o conhecimento do mundo. Esta crise se apresenta a nós como um limite no real que re-significa e re-orienta o curso da história: limite do crescimento econômico e populacional; limite dos desequilíbrios ecológicos e das capacidades de sustentação da vida; limite da pobreza e da desigualdade social. Mas também crise do pensamento ocidental: da "determinação metafísica" que, ao pensar o ser como ente, abriu a via da racionalidade científica e instrumental que produziu a modernidade como uma ordem coisificada e fragmentada, como formas de domínio e controle sobre o mundo. (LEFF, 2003, p.15-16) 


\section{CRISE ECOLÓGICA E EA NÃO FORMAL}

A Educação, a partir de saberes diversos, assim como o movimento ambiental/ecológico, é forjada na sociedade, portanto são frutos de um processo histórico, não isento das disputas de poder.

E, se a Educação pretender ser voltada para emancipação, somente logrará êxito pela conscientização (FREIRE, 2011). Dai a imperiosidade de conhecer a realidade para transformá-la (FREIRE, 2011, p. 37).

Assim, para conhecermos a realidade, entre outras exigências, é necessário ter acesso a informação, esforço que o ecologismo vem realizando através das denuncias e divulgação, por diversas formas, de estudos sobre a crise ecológica. Quanto mais informação, mais possibilidade de conhecimento e, por consequência, mais capacidade de transformação da atual crise ecológica opressora da vida humana e não humana. Dai a importância do ecologismo, desde seu nascedouro, em denunciar e alertar sobre os aspectos dessa crise.

A EA, para a lei ambiental brasileira, é entendida como "os processos por meio dos quais o indivíduo e a coletividade constroem valores sociais, conhecimentos, habilidades, atitudes e competências voltadas para a conservação do meio ambiente, bem de uso comum do povo, essencial à sadia qualidade de vida e sua sustentabilidade (Art. $1^{\circ}$, da Lei 9597/99).

Em que pese a Politica Nacional de Educação Ambiental (PNEA) classificar a EA em EANF e Educação Ambiental Formal (EAF), a Constituição Federal de 88 (CF/88) não diferenciou a importância do papel de ambas para assegurar o direito ao meio ambiente ecologicamente equilibrado, na promoção da "conscientização pública para a preservação do meio ambiente" (inciso, VI, $\S 1^{\circ}$, art. 225).

Segundo a PNEA, a EANF compreende "as ações e práticas educativas voltadas à sensibilização da coletividade sobre as questões ambientais e à sua organização e participação na defesa da qualidade do meio ambiente” (Art. 13, da Lei 9597/99). Das conclusões decorrentes dessa definição, podemos afirmar que os protestos promovidos pelo movimento ecológico contra a poluição, entre outras ações realizadas décadas antes 
da vigência da Lei da PNEA, já eram formas de concretizar a Educação Ambiental Não Formal (EANF) no cenário social complexo da crise ecológica, uma vez que visavam, entre outros fins, chamar a atenção para os problemas ambientais, na expectativa do envolvimento do cidadão, como forma de fortalecer a luta ecológica e pressionar governantes e capitalistas.

Outro entendimento decorrente é que para o ordenamento jurídico ambiental brasileiro $^{8}$, notadamente com base na Lei da PNEA, a EANF não é uma exclusividade concebida e/ou executada pelas organizações não governamentais, como pode parecer numa analise comparativa com a EAF. Pois além das ONGs, adequadamente, a lei convoca a escola, a universidade e os meios de comunicação de massa para promoverem a EANF, além de empresas públicas e privadas. A questão é, mais que identificarmos se tais atores realizam uma EANF, trata-se de compreender qual EANF é realizada; a quem ela beneficia e qual fim se propõe.

No caso da escola, podemos exemplificar a EANF materializada em projetos, que corresponde a $66 \%$ das ações em EA. Via de regra se tratam de projetos que abordam a questão ambiental de forma reducionista, como os de reciclagem ou plantio de árvores, extremamente comuns quando se trata de realizar a EA no ambiente formal.

(...) muitos programas de educação ambiental na escola são implementados de modo reducionista, já que, em função da reciclagem, desenvolvem apenas a Coleta Seletiva de Lixo, em detrimento de uma reflexão crítica e abrangente a respeito dos valores culturais da sociedade de consumo, do consumismo, do industrialismo, do modo de produção capitalista e dos aspectos políticos e econômicos da questão do lixo. (LAYRARGUES, 2002, p.01)

Nas universidades, encontramos como exemplo diversos eventos e cursos que tratam da EA. Importante destacar que para o Programa de Pós-graduação em Educação Ambiental (PPGEA) ${ }^{9}$, da Universidade Federal de Rio Grande (FURG), a EANF envolve

8 Outros diplomas tratam da EA, como a Lei 8.171/91 que dispõe da Política Agrícola Nacional a qual reservou um destaque para a EA, no inciso V, do art. 19, estabelecendo que o Poder Público, ou seja, todos os entes federados (município, estado, União e Distrito Federal), em todas esferas (Executivo, Legislativo e Judiciário), devem "desenvolver programas de educação ambiental, a nível formal e informal, dirigidos à população" (SOLER, 2011, p.146)

9 Tem "por objetivo geral a formação de profissionais qualificados para o exercício de atividades de ensino, pesquisa e extensão e para a produção de conhecimento no campo da Educação Ambiental" (art. 2 do Regimento Interno). 
as questões socioecológico-ambientais nos campos não formais e informais de Educação Ambiental. Enfatiza a dimensão ético-estética, a diversidade e alteridade dos grupos sociais, as relações entre a Educação Ambiental, os gêneros, as gerações humanas em todas as suas idades, o desenvolvimento humano e sistêmico, a compreensão da interligação dos espaços ambientais, da saúde coletiva e da qualidade de vida dos sujeitos e das instituições e organizações sociais. (Ítem 5.3 Projeto Pedagógico PPGEA/FURG)

E tem por fim o

comprometimento dos pesquisadores envolvidos na restituição dos resultados dos trabalhos às comunidades investigadas (princípio e fim das pesquisas), assim como a participação de comunidades integradas nos processos decisórios do manejo de ecossistemas, preferentemente costeiros, em busca da construção coletiva de sociedades sustentáveis e utopias concretizáveis. (ítem 5.3 Projeto Pedagógico PPGEA/FURG)

O PPGEA tem também contribuído para o desenvolvimento com a EANF. Um exemplo que merece destaque, pelo seu conteúdo e pioneirismo foi $1^{\circ}$ Congresso de Educação Ambiental na Área do Mar de Dentro, proposto pelo governo do estado RS e realizado, no ano de 2001, em conjunto com o PPGEA, com o apoio de Organizações Não-Governamentais (ONG's), como o CEA e do Conselho Regional de Desenvolvimento da Região Sul (COREDE/Sul) (Diário Popular, 2001).

Já, nas mídias, a EANF se manifesta em programas especiais, entrevistas com envolvidos na luta ecológica ou não, em redes sociais e blogs ditos alternativos à imprensa comercial, como são o Ecodebate, a EcoAgencia ligada ao Núcleo de Ecojornalistas do RS (NEJRS) e do próprio CEA, entre outros.

No caso das empresas, além de encontrarmos sua participação nos exemplos acima citados, merece mais atenção à EA executada de forma obrigatória por força de lei, decorrente dos processos de licenciamento ambiental, conforme as regras vigentes. Contudo, é uma manifestação da EA a qual, como as demais, requer aperfeiçoamento e acompanhamento organizado e orgânico da sociedade civil.

(...) a EA na gestão ambiental pública atua neste espaço possível de participação dos grupos subalternos pelo controle social do Estado, disciplinado pelas regras do licenciamento ambiental, que privilegia o saber perito, a técnica e as decisões centradas no órgão ambiental, pautado na maioria das vezes pela inexorabilidade da obra e/ou atividade. Na concorrência por este espaço ainda poder-se-ia encontrar, contraditoriamente, uma EA Transformadora, mas, por outro lado, uma EA Conservadora, a qual tem sido a tendência. (DIAS, 2014, p.123) 
A EANF não tem obrigatoriedade de acontecer permanentemente no mesmo local, como o caso da EAF, num escola, p. ex., mas pode se dar em qualquer ambiente, construído ou não, como um banhado, um campo (típicos do Bioma Pampa), uma escola ou ainda num parlamento, por um longo período ou de forma esporádica.

Contudo a lei da PNEA faz um diagnostico equivocado, ou no mínimo parcial, no que tange àqueles que devem receber a EANF, pois a direciona explicitamente, às populações tradicionais e aos agricultores, como se todos e/ou somente esses tivessem responsabilidade pelo tamanho da crise ecológica ou de zelar pelo ambiente, diferentemente do que estabelece a $\mathrm{CF} / 88$, não mencionando os grandes proprietários de indústrias e de áreas rurais destinadas ao agronegócio, os capitalistas da cidade e do campo.

Quanto a substância, a EANF pode vir a ser transformadora ou não. Somente será, se a mesma partir do entendimento de que realidade atual (capitalista e antropocêntrica) é opressora da vida humana e não humana, impedindo-as de virem a ser mais (FREIRE, 2011, p.58) associado ao entendimento de que a Educação tem papel de destaque na busca pela libertação, pelo termino dessa opressão.

Bem mais relevante que se debruçar sobre a aparência da EA, se Formal ou NãoFormal, é tratar da analise da EA quanto ao seu conteúdo, ou seja, se a EA pensada e praticada se propõe a transformar a realidade opressora ou se pretende mantê-la, nas bases paradigmáticas vigentes, com alguns ajustes.

Dessa forma, na disputa teórica e pratica da EA, formal ou não formal, nos deparamos como a mesma divisão central do movimento social voltado para o tema ambiental: de um lado os ambientalistas, cuja proposta é enfrentar a crise ecológica sem mudar as estruturas sociais, fazendo apenas algumas mudanças pontuais, "algo como reformar o mundo para torna-lo sustentável" (QUINTAS, 2009, p.40); e os ecologistas, os quais contestam o modelo de sociedade vigente, defendendo que a superação da crise ecológica somente será possível numa outro paradigma de mundo.

$\mathrm{Na}$ perspectiva do ecologismo, o qual problematiza, critica e, de forma majoritária, busca transformar a base material da sociedade, a crise ecológica 
natureza faz dela um outro ser a ser dominado (Porto-Gonçalves, 2002), para usá-la como fonte inesgotável de matéria prima e deposito de resíduos (QUINTAS, 2009, p.42)

Tal assertiva reconhece um cenário decorrente da visão antropocêntrica de natureza, formadora da base teórica para o ideal hegemônico de civilização. Dai que os ecologistas

não compreendem ser possível a vida numa Terra com seus metabolismo em equilíbrio, sem uma radical mudança na organização social e na matriz econômica, com o consequente afastamento do antropocentrismo. Já os segundos [ambientalistas] não entendem ser necessária uma transformação profunda na relação sociedade Natureza para que se alcance a sustentabilidade , ou melhor, o Desenvolvimento Sustentável (DS) e, por isso mesmo, não lutam por ela e, portanto, convivem, não raras vezes, confortavelmente e até de forma vantajosa com o antropocentrismo. (SOLER, 2011, p.34)

O ecologismo carrega uma proposta emancipatória e revolucionária, colocado “em questão o conceito de Natureza que tem vigorado e, como ele perpassa o sentir, o pensar e o agir de nossa sociedade, no fundo coloca em questão o modo de ser, de produzir e de viver dessa sociedade" (GONÇALVES, 2004, p.28).

Importa uma EAF ou uma EANF que tenha por fim o enfrentamento da crise ecológica e, dessa forma, do capitalismo e do antropocentrismo.

A expectativa é empreender uma nova leitura para esse fazer educativo [da EA], reavaliando seus fundamentos e suas posturas, para no limite reconhecer que, na diversidade interna de opções politico-pedagógicas da educação ambiental, invariavelmente despontam duas situações diversas como resultado da intencionalidade pedagógica: a reprodução da sociedade atual tal qual esta, ou sua transformação. (LAYRARGUES, 2009, p.11)

De qualquer forma, há que se ter em conta que a transformação social não é uma tarefa capaz de ser realizada somente pela EA ou mesmo pela Educação, mas, certamente, deve contar com elas.

La gente no cambiará sus valores simplesmente porque se les 'enseñen' otros diferentes (...) cuál es, entonces, el verdadeiro camino hacia delante, si no há de ser unicamente, o en gran medida al menos, el de la educación? Debe ser el de la búsqueda de una reforma de la base material de la sociedade, concurrente com el cambio educacional (PEPPER Apud DOBSON, 1997, p.181)

Portanto, a EA (formal ou não formal) deve ter, no mínimo, um duplo papel, para ser considerada transformadora: superar a crise social e superar a crise ecológica, ambas decorrentes do paradigma capitalista/antropocêntrico, refletidos na base material da 
sociedade. A superação de apenas uma dessas facetas da crise civilizatória é enfrentar parte do problema e, portanto, não é uma superação propriamente dita, pois tal crise deve ser pensada, entendida e, sobretudo, sobre ela agir considerando sua totalidade.

\section{IMPLICAÇÕES LOCAIS DO MODELO DE DESENVOLVIMENTO HEGEMÔNICO NO MUNDO E RESISTÊNCIA E LUTA ECOLÓGICA}

A sociedade brasileira nos anos das décadas de 60/70 do século que passou, vivenciava um contexto delimitado pela repressão às liberdades individuais ao lado de uma politica governamental voltada para a implantação de processo de crescimento acelerado, notadamente através da industrialização e de grande obras de infraestrutura, com nível baixo ou nenhum de politica ambiental protecionista paralela.

No caso do munícipio de Rio Grande, junto ao estuário da Laguna dos Patos, no Rio Grande do Sul, o regime ditatorial, o arbitrou como de Interesse de Segurança Nacional $^{10}$, lhe impondo um projeto de crescimento econômico, cuja estratégia passava pela ampliação do Porto e a instalação de infraestrutura para comportar o Distrito Industrial de Rio Grande (DIRG), visando relações com o mercado externo, numa busca pela inserção com a globalização capitalista.

Dessa forma, na década de 70, Rio Grande recebeu uma gama considerável de recursos públicos para que tivesse instalada uma infraestrutura voltada para o processo de operação portuária, notadamente voltado para a exportação.

Tal município costeiro, que já tinha experimentado um perfil industrial diverso, constituído pela industrial têxtil, de cigarros, de alimentos (como bebidas, bolachas e, notadamente, pescado) e até refinaria de petróleo, passou a receber também empresas de fertilizantes sintéticos, junto ao DIRG e ao porto de Rio Grande.

\footnotetext{
Por meio do II Plano Nacional de Desenvolvimento (II PND), que englobou o I Plano Nacional de Fertilizantes, o Estado procurou reduzir a dependência externa, elevando a participação da produção nacional na oferta total de produtos finais. Investiu-se, principalmente, na produção de matérias-primas nitrogenadas e fosfatadas. (FERNANDES, GUIMARÃES e MATHEUS, 2009, p.205)
}

10 Conforme Lei 5449/68, declara de interesse da segurança nacional, nos termos do art. 16, § $1^{\circ}$, alínea b, da Constituição os Municípios que especifica. 
A instalação e operação dessas empresas somadas as obras de infraestrutura que o regime da ditadura civil/militar proporcionava levaram, não só a uma mudança da paisagem, mas também a múltiplos impactos ambientais, como aterramento de banhados e corpos hídricos, supressão de dunas, ocupação de APPs, como o caso do entorno da Laguna dos Patos e do Saco da Mangueira, não somente para fins de atividades portuárias, mas também, especialmente em razão delas, para a expansão urbana informal. Implicações locais do modelo de desenvolvimento hegemônico no mundo.

Em decorrência, com novas unidades das indústrias de fertilizantes, algumas empresas desse ramo já se encontravam instaladas em Rio Grande desde a década de 50 do século passado (FERREIRA, 2014, p.75), acrescentou-se a parte do cenário local a poluição atmosférica gerada por tais indústrias, visivelmente a olho nu, agora, ainda mais detectável, devido a essa intensificação dessa atividade, causando também outros impactos ambientais, que não só cênico.

De tanto visualizar e sentir tal poluição, a sociedade decidiu agir e resistir a mesma de varias maneiras, com destaque para as criticas publicas na imprensa local, uma forma pioneira de EA nos tempos contemporâneos, protagonizada por pessoas que tinham preocupação com a qualidade ambiental e que, aliadas a outros fatos e fenômeno sociais, proporcionaram as bases para a constituição do movimento ecológico. Dialeticamente, do mesmo contexto de onde a poluição atmosférica emanava, foi forjada uma organização social visando sua contestação e o seu fim.

\section{O CEA E O PIONEIRISMO NA EA NÃO FORMAL}

No cenário de crise ecológica local, evidentemente relacionado com o que acontecia no mundo, ainda nos anos 70, vozes materializaram um pensamento analítico e critico em relação ao processo de industrialização de Rio Grande, com destaque para as publicações no Jornal Agora (mas não somente), das denominadas Crônicas Ecológicas, entre os no final dos anos de 70 até meados dos 80 (ESTEVAN, 2013).

Sem duvida, uma das motivações dessa resistência à industrialização foi provocada por um fenômeno de fácil percepção: a poluição do ar, conforme acima mencionado. Assim, a partir da problematização de sua complexidade, num primeiro 
momento ainda incipiente, a mídia disponível a época (o jornal) serviu de instrumento destacado para os primeiros passos da EANF contemporânea. As publicações foram promovidas por três ativistas ecológicos, que viriam posteriormente fundar ${ }^{11} \mathrm{o}$ CEA.

Tal fenômeno, cabe registrar, foi posterior ao surgimento do movimento ecológico organizado na hoje denominada Região Metropolitana de Porto Alegre (RMPA), destacadamente pela fundação da Associação Gaúcha de Proteção do Ambiente Natural (AGAPAN), em 1972, bem como da chamada Maré Vermelha, na Praia do Hermenegildo, em Santa Vitoria do Palmar, na fronteira com o Uruguai, no final da década de 70. Fatos que marcaram determinantemente a construção da luta ecologia no RS.

As publicações sobre as questões ambientais nos jornais de circulação local e o processo de organização coletiva, reunindo pessoas que a época ou há mais tempo já demonstravam preocupação com tais temas, formaram condições históricas que, em sinergia, representaram uma reação aos impactos negativos decorrentes do modelo econômico em implantação no município portuário, tendo como um dos focos centrais a critica a poluição industrial, acima descrita, sem no entanto propor, de forma explicita uma transformação radical da sociedade.

Dessa forma, a EANF, através das crônicas publicadas e o movimento ecológico que emergia convergiram na problematização e numa proposta de transformação, em determinada medida, da realidade atinente a poluição atmosférica constatada. O grupo que já atuava desde meados da década de 70, agregou novos apoiadores e fundou uma sociedade civil de viés ambiental, motivados pelo entendimento de que era necessário enfrentar a degradação ambiental verificada em Rio Grande, notadamente no seu Porto e Distrito Industrial, por uma via cidadã organizada e institucionalizada, se valendo da abertura democrática a época.

Dessa convergência, somado a outros fatores, em 1983, foi fundado o CEA, com a finalidade, entre outras, de "atuar de forma a minimizar ou erradicar efeitos danosos ao ambiente" (Estatuto do CEA).

Assim, o CEA não só deu único, como institucionalizou o movimento

11 A época das publicações eram politica e administrativamente ligados ao Núcleo de Rio Grande da Associação Gaúcha de Proteção do Ambiente Natural (AGAPAN) a exemplo de vários outros núcleos existentes pelo estado. 


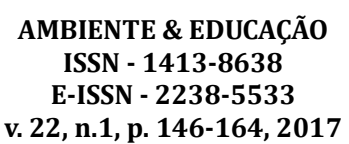

ecológico/ambiental em Rio Grande e na região sul do RS, promovendo a luta ecológica por diversos meios como a EANF, de forma pioneira, valendo-se, para tanto, de todos os instrumentos disponíveis a época, como reuniões com o Poder Público e com outras organizações da sociedade civil e de trabalhadores, produção de documentos, de adesivos, realização de campanhas, elaboração de artigos em jornais, publicações diversas e atividades de rua, é claro, como passeatas e até bicicletas, mais recentemente.

A tentativa de enfrentar os problemas ambientais e/ou solucionar conflitos ambientais de forma dialógica (reuniões) com diferentes, mas não antagônicos, como uma ONG ecológica e um órgão ambiental público, no mínimo, apresentava duas finalidades educativas: a) influenciar na construção de politicas públicas ambientais, uma vez que educar é uma ato politico e coletivo (FREIRE, 2011, p.71) e; b) colaborar para a promoção da consciência ambiental (de forma reciproca, pois ao se reunir e dialogar há uma troca de saberes). A promoção da consciência ambiental também se buscava pela divulgação de tais atividades pela imprensa.

\section{Entidade ecológica reúne-se com DMA}

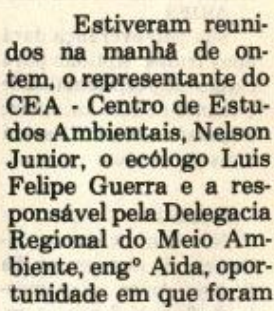

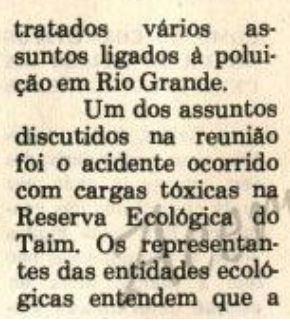

empresa de transportes deveria ser processada judicialmente $e$, inclusive, já estão tomando atitudes nesse sentido.

A representante da Delegacia confirmou que a Secretaria de Saúde e do Meio Ambiente emite um documento

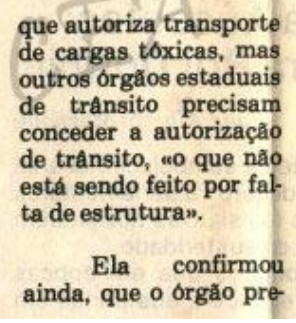

tende acionar judicialmente a transportadora baseado na Lei do Meio Ambiente, mas ressalta que "os municipios devem fazer leis que determinem e controlem o transporte de cargas toxicas, prevendo medidas punitivas para os transgressoresn.

Figura 1: - Notícia de Jornal.

Fonte: Jornal Agora, 1985.

A estratégia de divulgar o máximo possível as ações e atividades de luta ecológica do CEA na imprensa fazia com que a informação ambiental atingisse, de alguma forma, a um numero indeterminado de pessoas (leitores/telespectadores), colaborando para o processo de conscientização sobre os problemas ambientais e seus impactos no cotidiano, sobretudo, por que essa era a forma mais eficiente de fazer com que o maior numero de pessoas tivessem acesso aos fatos dessa ordem, até então pouco abordados. A mídia é uma clara e importante maneira de promover a EANF. 


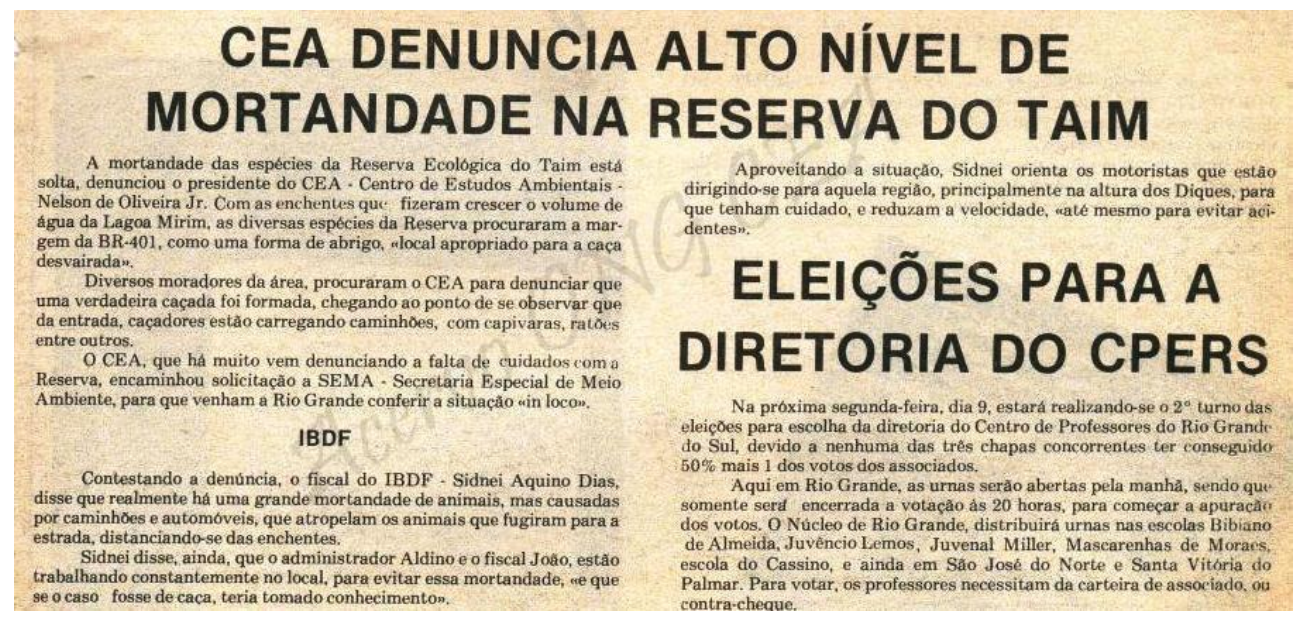

Figura 3: - Notícia de Jornal.

Fonte: Jornal Agora, 1984.

Outra maneira de buscar chamar a atenção para sua luta ecológica, foi uso de artigos elaborados pelos militantes do CEA e publicados em jornais. Uma indiscutível expressão da EANF 


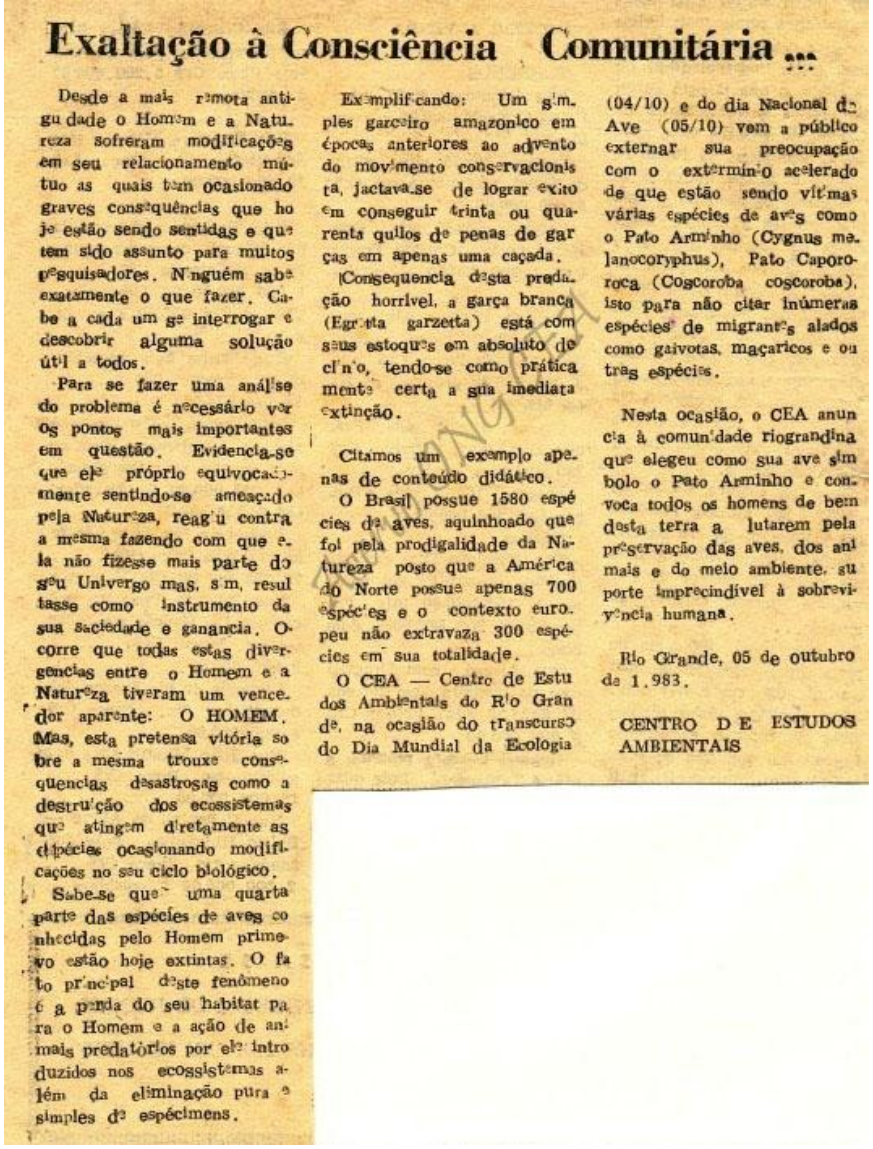

Figura 5: - Artigo em Jornal. Fonte: Jornal Rio Grande, 1983.

Nesse sentido, as atividades de rua, além de demonstrarem a aglutinação social em torno de um tema, no caso da luta ecológica, também colaboram para a EANF, pois repercutem de diversas formas na sociedade, além, é claro, de receberem atenção da imprensa. 
AMBIENTE \& EDUCAÇ̃̃o

ISSN- 1413-8638

E-ISSN - 2238-5533

v. 22, n. 1, p. 146-164, 2017

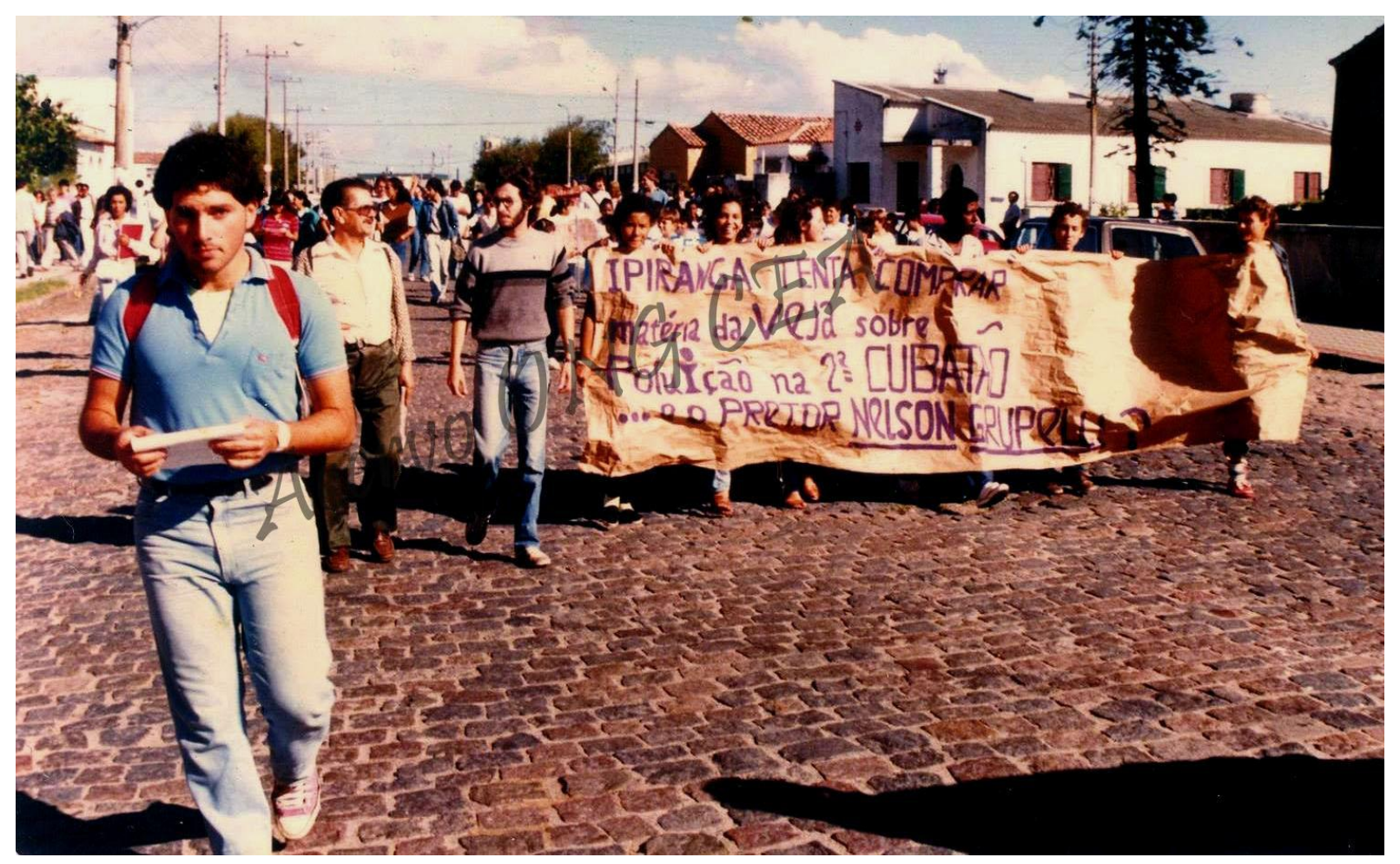

Figura 4: - Foto de Passeata contra a Poluição do Ar.

Fonte: Acervo ONG CEA, 1984.

Outra forma que o CEA se valeu (e ainda se vale) para promover a EANF foi a como e elaboração e a distribuição de material visual, como adesivos com mensagens a favor da proteção ambiental, como: "extinção é para sempre, simplesmente preserve”.

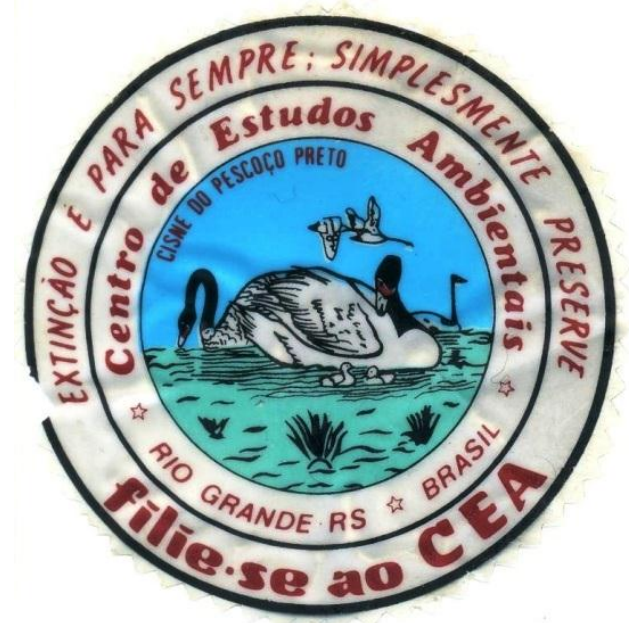

Figura 2: - Adesivo.

Fonte: Arquivo do CEA, década de 1980. 
No campo da EANF, de todos os agentes que a lei indica como promotores/parceiros para sua realização, o CEA não estabeleceu parcerias estratégicas e/ou prioritárias somente com empresas privadas, salvo alguns apoios em atividades pontuais e organizadas por múltiplas instituições. Não esta na caracterizada EANF promovida pelo CEA firmar, de forma isolada, parcerias com empresas privadas, o que poderia configurar uma inequívoca contradição na busca pela transformação social, ao alia-se com aqueles que colaboram com a manutenção do modelo societário dominante, antropocêntrico e capitalista, como já mencionado.

\section{CONSIDERAÇÕES FINAIS}

Se na década de 60 o mundo viveu um significativo processo de industrialização, a luta ecológica teve também lá seu nascedouro, contestando, majoritariamente, o modelo societário produtivista, consumista e injusto.

A visão antropocêntrica de natureza, construída historicamente, ao lado da economia capitalista, constituem as bases para a crise ecológica, que é uma crise, em ultima instância, do modelo de civilização.

A EANF deve praticar ações "voltadas à sensibilização da coletividade sobre as questões ambientais e à sua organização e participação na defesa da qualidade do meio ambiente" (Art. 13, da Lei 9597/99). Contudo, mais que a aparência da EA (Formal ou Não-Formal) importa seu conteúdo, ou seja, se a EA se propõe a transformar ou manter a realidade opressora e, portanto, a crise ecológica.

De forma injusta, PNEA destaca parte de seu objetivo para setores sociais mais oprimidos, como populações tradicionais ou agricultores familiares, cuja a escala de impacto ambiental é ínfima, ao mesmo tempo que desresponsabilizam grandes empresas que externalizam os seus custos ambientais, causando danos ao ambiente e com prejuízos para todas as formas de vida, como o caso das pessoas em maior situação de vulnerabilidade.

No caso do munícipio de Rio Grande, com o projeto de crescimento econômico imposto pelo regime de exceção, não só levou a ampliação do conjunto das indústrias de fertilizantes, com sua consequente poluição, como contribui para o surgimento do 
movimento ecológico, notadamente através do CEA, o qual foi pioneiro na EANF, prevista na Lei da PNEA, entrando para o ordenamento jurídico ambiental brasileiro posteriormente aos protestos promovidos contra a poluição atmosférica e outras formas de poluição, notadamente nos anos das décadas 70/80, do século passado.

A transformação da sociedade não será possível somente com a EA, mas sim de forma associada com outras medidas, como a transformação de sua base material.

A EA (formal ou não formal) para ser considerada transformadora, deve ter, no mínimo, um duplo papel: superar a crise social e a ecológica, combatendo o paradigma capitalista/antropocêntrico.

\section{REFERÊNCIAS}

ACSELRAD, Henri; MELlO, C. C.; BEZERRA; G. N. O que é Justiça Ambiental. Rio de Janeiro: Garamond. 2009;

CENTRO DE ESTUDOS AMBIENTAIS. Blog construído e mantido pelo Centro de Estudos Ambientais, [2016]. Disponível em: http://centrodeestudosambientais.wordpress.com/

DIAS, Eugênia Antunes. Desculpe o Transtorno, Estamos em Obras para Melhor Servi-Lo! A Educação Ambiental no Contexto da Apropriação Privada da Natureza no Licenciamento Ambiental. Rio Grande: FURG, 2014. 248 p. Tese (Doutorado)-Programa de Pós-Graduação em Educação em Educação Ambiental, Universidade Federal de Rio Grande, Rio Grande, 2014.

DOBSON, A. Pensamiento Político Verde. Barcelona: Paidós. 1997.

ESTEVAN, Bread Soares. História, Crítica e a Educação Ambiental Sob o Prisma das Crônicas da Associação Gaúcha de Proteção do Ambiente Natural no Extremo Sul do Brasil (1978-81). Rio Grande: FURG, 2013. 148 p. Dissertação (Mestrado) -Programa de Pós-Graduação em Educação em Educação Ambiental, Universidade Federal de Rio Grande, Rio Grande, 2013.

FERREIRA, Washington Luiz dos Santos. A Poluição Industrial no "Mar De Dentro" na Perspectiva da Educação Ambiental Crítica e Transformadora. Rio Grande: FURG, 2014. 263 p. Dissertação (Mestrado) -Programa de Pós-Graduação em Educação em Educação Ambiental, Universidade Federal de Rio Grande, Rio Grande, 2014.

FERNANDES, Eduardo; GUIMARÃES, Bruna e MATHEUS, Romulo. Principais Empresas e Grupos Brasileiros do Setor de Fertilizantes. BNDES. 2009. Disponível em:

https://web.bndes.gov.br/bib/jspui/bitstream/1408/2667/1/BS\%2029\%20Principais\%20e

mpresas\%20e\%20grupos\%20brasileiros_P.pdf

FREIRE, Paulo. Pedagogia do Oprimido. Rio de Janeiro: Paz e Terra, 2011.

FURG. PPGEA. Projeto Pedagógico. Disponível em:

http://www.educacaoambiental.furg.br/ 
GONÇALVES, Carlos Walter Porto. Os (Des) Caminhos do Meio Ambiente. São Paulo: Contexto, 2004.

Jornal Agora. Rio Grande. jul. 1984.

Jornal Agora. Rio Grande. set. 1985.

Jornal Diário Popular. Mar. 2001. Disponível em: http://srvnet.diariopopular.com.br/18_03_01/mr150314.html

Jornal Rio Grande. Rio Grande. ago.1983.

LAYRARGUES, P. P. O cinismo da reciclagem: o significado ideológico da reciclagem da lata de alumínio e suas implicações para a educação ambiental. In: LOUREIRO, C. F. B.; LAYRARGUES, P. P.; CASTRO, R. de S. (Orgs.). Educação ambiental: repensando o espaço da cidadania. São Paulo: Cortez, 2002. p. 179-219.

LAYRARGUES, Philippe Pomier. Repensar a Educação Ambiental: Um Olhar Critico. São Paulo: Cortez. 2009.

LEFF, Enrique. A Complexidade Ambiental. São Paulo: Editora Cortez, 2003.

LÖWY, Michael. Ecologia e Socialismo. São Paulo: Cortez. 2005.

MARQUES, Luiz. Capitalismo e Colapso Ambiental. Campinas: UNICAMP. 2015.

MONTIBELLER-FILHO, Gilberto. O Mito do Desenvolvimento Sustentável. Florianópolis: Editora da UFSC, 2008.

PEPPER, David. Ambientalismo Moderno. Lisboa: Instituto Piaget, 1996.

QUINTAS, José Silva. Repensar a Educação Ambiental: Um Olhar Critico. São Paulo: Cortez. 2009.

SOLER, Antônio C. P. Antropocentrismo e Crise Ecológica: Direito Ambiental e Educação Ambiental como meios de (re) produção ou superação. Rio Grande: FURG, 2011. 177 p. Dissertação (Mestrado)- Programa de Pós-Graduação em Educação em Educação Ambiental, Universidade Federal de Rio Grande, Rio Grande, 2011. 